\title{
Brainstem tuberculomas
}

\author{
Beuy Joob $^{1} \cdot$ Viroj Wiwanitkit ${ }^{2}$
}

Received: 16 February 2017 / Accepted: 6 March 2017 /Published online: 14 March 2017

(C) Springer-Verlag Wien 2017

Dear Editor,

The recent publication on brainstem tuberculomas [1] is very interesting. Sadashiva et al. [1] noted that "Intracranial tuberculoma may present with or without meningitis" and "Antitubercular therapy has a very good prognosis, though the duration of therapy required may be longer." We would like to share ideas and experiences on this issue. In tropical countries, the intracranial tuberculoma is not uncommon and the diagnosis is difficult. In our setting, the diagnosis is usually by clinical diagnosis and a pathological specimen is rarely derived; a negative finding on the derived pathological specimen is common [2]. Sometimes, the lesion might be missed diagnosis as a malignant brain tumor and the surgery

Beuy Joob

beuyjoob@hotmail.com

Sanitation 1 Medical Academic Center, Bangkok, Thailand

2 Hainan Medical University, Hainan, China is usually done in those cases [3]. The use of antitubercular drug is usually the main therapeutic of choice in suspicious cases. However, the difficulty is the selection of appropriate chemotherapy regimen. Due to the increase in prevalence of drug resistance, the adjustment of the regimen corresponding to the local drug resistance epidemiology is needed.

\section{Compliance with ethical standards}

Conflict of interest None.

\section{References}

1. Sadashiva N, Tiwari S, Shukla D, Bhat D, Saini J, Somanna S, Devi BI (2017) Isolated brainstem tuberculomas. Acta Neurochir (Wien). doi:10.1007/s00701-017-3108-1

2. Phuenpathom N, Mitarnun W (1989) Intracranial tuberculoma in Thailand: report of a case and review of the literature. J Med Assoc Thail 72(6):355-360

3. Prachasilchai P (2012) Cerebral tuberculoma presented as primary malignant brain tumor: a case report. J Med Assoc Thail 95(Suppl 3): S131-S133 